\title{
TRADUÇÃO LITERÁRIA E VARIAÇÃO LINGUÍSTICA EM ONE CHRISTMAS EVE, DE LANGSTON HUGHES
}

\author{
LITERARY TRANSLATION AND LINGUISTIC VARIATION IN LANGSTON \\ HUGHES' ONE CHRISTMAS EVE
}

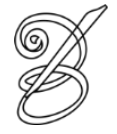 \\ Carolina Geaquinto PAGANINE* \\ Universidade Federal Fluminense, Brasil \\ Isadora Moreira FORTUNATO** \\ Universidade Federal Fluminense, Brasil
}

\begin{abstract}
Resumo: Este trabalho apresenta algumas reflexões sobre a nossa tradução do conto One Christmas Eve, de Langston Hughes (1902-1967), parte da obra The Ways of White Folks (1934). Temos como objetivo analisar a possibilidade de representação de variedades linguísticas nos sistemas literários fonte e alvo (americano e brasileiro) e explorar soluções tradutórias para tais variedades, ligadas à representação de grupos de fala, compreendendo sua legitimidade, sistematicidades e entendendo que elas caracterizam os falantes no texto literário. São discutidas teorias da tradução que tratam de marcas de oralidade (BANDIA, 2015; ROSA, 2015) e de variação linguística em relação ao African American Vernacular English (AAVE) e ao português brasileiro (BAGNO, 2012; EZGETA, 2012; LABOV, 1972; LUCCHESI, 2009). Primeiramente, apresentamos o contexto de produção da obra e as questões raciais, sociais e ideológicas que este suscita. Além disso, discutimos alguns aspectos das fases literárias do autor e a influência da Harlem Renaisssance e do movimento modernista norteamericano na escrita do conto aqui apresentado e traduzido. Em seguida, examinamos as variedades linguísticas presentes no texto-fonte e alvo e os aspectos que orientaram nossas escolhas, tendo como princípio norteador marcar a alteridade no texto e evitar uma tradução que realize uma homogeneização dos modos de fala e que apague identidades veiculadas pela representação da linguagem falada no texto literário. Com isto, consideramos $\mathrm{o}$ ato de tradução como aquele que estabelece um texto em outra cultura a partir de uma reescrita do texto-fonte, um ato que vê a língua a partir de sua dimensão cultural e social. A partir disso, situamos a nossa prática tradutória a partir da perspectiva de que os tradutores têm um papel ativo e ativista frente à homogeneização das línguas e ao apagamento de identidades de grupos marginalizados ao decidirem por recriar a pluralidade de vozes textuais, tendo em vista a tradução como um lugar privilegiado em que duas instâncias se encontram e podem ser examinadas por uma abordagem analítica e crítica.
\end{abstract}

Palavras-chave: Tradução comentada. Oralidade. Variação linguística. Socioleto literário. Langston Hughes.

\begin{abstract}
In this paper we present a discussion on our translation of Langston Hughes' (1902-1967) short story One Christmas Eve (1934), from The Ways of White Folks (1934). The aim is to explore possible choices on translating linguistic varieties that represent a speech group in the written text, considering that that these linguistic varieties are legitimate, systematic and that they characterize speakers in fictional texts. We base our analysis on theories about the representation of orality in translation (BANDIA, 2015; ROSA, 2015) and theories that examine linguistic variation, more specifically African American Vernacular English and Brazilian Portuguese (BAGNO, 2012; LABOV, 1972, EZGETA, 2012, LUCCHESI, 2009). At first, we provide the author's context of writing, racial, ideological and social issues that this text brings into light. Secondly, we discuss the author's literary phases and the influence of the postulates of Harlem Renaissance and American modernism in the composition of the short story here analyzed and translated. Then, we discuss the use of linguistic varieties in the process of translation (varieties that both source and target text present) and aspects that oriented the choices made in the target text, understanding that our main point is to mark otherness in the text and to avoid a translation that homogenizes and erases identities represented by speech patterns in the literary text. This led us to consider how the act of translation places a text in another culture through a rewriting of a source text, an act that understands language in its cultural
\end{abstract}


and social dimension. Based on those perspectives, we see our translation practice from the point of view that translators have an activist role against the homogenization of languages the erasure of identities of marginalized groups when translators decide to recreate the plurality of textual voices, considering translation as a privileged place in which two instances meet and are examined with an analytical and critical approach.

Key-words: Translation with commentary. Orality. Linguistic variation. Literary sociolect. Langston Hughes.

RECEBIDO EM: 19 de agosto de 2019

ACEITO EM: 03 de dezembro de 2019

PUBLICADO EM: janeiro 2020 


\section{Introdução}

$\mathrm{N}$

este artigo apresentamos a nossa tradução comentada do conto One Christmas Eve, de Langston Hughes (1902-1967), que faz parte da obra The Ways of White Folks, tradução e os comentários levam em consideração a representação da variação linguística e das marcas de oralidade, estilo e estratégias de tradução de prosa (BRITTO, 2012) e estudos sobre o African American Vernacular English (LABOV, 1972) e o português brasileiro (BAGNO, 2012; LUCCHESI, 2009; 2012). Para apoiar nossas escolhas tradutórias, este artigo também analisa elementos contextuais como o movimento cultural Harlem Renaissance, no qual o autor estava inserido, suas influências para a produção da obra e as características estilísticas do conto propriamente dito.

A proposta de traduzir este conto tem como premissa manter na tradução para o português brasileiro a alteridade expressa no texto-fonte. Este 'Outro', que não é o hegemônico dentro de uma sociedade (BONNICI, 2009) se expressa textualmente através da representação na literatura da variedade linguística African American Vernacular English (AAVE), variedade falada pela população afro-americana. Entendendo a composição histórica dos países da América, percebe-se a construção destes “outros" como todos aqueles que não a elite detentora de poder econômico e político. Essa elite, por sua vez, impõe uma soberania cultural com a abertura desta mesma cultura para que seja apenas um espaço para suas próprias construções simbólicas e ideológicas. Porém, no processo de tomada de consciência (FANON, 2005 [1961]) e de elementos do universo da cultura, esses 'outros' criam a possiblidade de afirmação a partir da própria expressão criativa.

No caso da produção literária de Langston Hughes, esses aspectos se fazem, por exemplo, na presença de personagens afro-americanos trazidos da margem da sociedade e da representação na literatura para o centro em sua narrativa por meio dos temas que o autor aborda, como a segregação racial, vulnerabilidade econômica, injustiça social, lógica capitalista e racista, e, no aspecto formal, por meio da representação da variedade linguística, o African American Vernacular English (AAVE). Essa técnica literária de marcar a oralidade revela a expressão de identidade racial do autor e de seu grupo étnico e linguístico na sociedade americana.

Ao propor um texto traduzido com foco na análise e tradução de marcas de oralidade, este trabalho se propõe a debater fatores linguísticos, literários e socio-históricos relativos a 
questões raciais e sociais e propor uma reflexão sobre como isso pode ser trabalhado durante o ato tradutório e quais produtos pode gerar.

\section{Autor e contexto}

O autor, James Mercer Langston Hughes (1902-1967), nasceu em Joplin, no estado do Missouri, Estados Unidos, em uma época anterior ao Movimento dos Direitos Civis, portanto, uma época em que a igualdade de condições sociais, políticas e econômicas não se fazia presente. Era um período de incertezas, os afro-americanos não tinham proteção legal contra a discriminação racial no país (TIDWELL; RAGAR, 2007, p. 2), não eram tratados como cidadãos plenos, principalmente no Sul, onde as leis de $\mathrm{Jim}_{\mathrm{Crow}}{ }^{1}$ vigoravam. Na verdade, durante o período em que durou a segregação racial no sul dos Estados Unidos, a lei assegurava que essa segregação fosse instalada e cumprida nas diversas instituições sociais como um todo e na vida cotidiana.

Em sua fase adulta, quando Langston Hughes já estava em Nova Iorque, o autor passou a fazer parte do movimento artístico e cultural conhecido por Harlem Renaissance (1917-1935).

36 Após ingressar na Lincoln University em 1925, obteve apoio para publicar seu primeiro livro de poemas que obteve atenção do público-leitor, The Weary Blues (1926). A publicação desta e das obras poéticas seguintes ajudou a estabelecer o estilo do escritor e como seria reconhecido no sistema literário americano.

Na década de 1930 publicou The Ways of White Folks (1934), seu primeiro livro de contos, dentre os quais figura One Christmas Eve, cuja tradução comentada realizamos. A obra foi publicada em um contexto de dificuldade econômica, pois o país ainda se recuperava dos efeitos da Grande Depressão e nesta época Hughes estava em uma fase em que sua expressão política e literária era mais confrontadora ao se comparar com a produção da década de 1920. Segundo Robert Young: "enquanto a poesia de Hughes de 1920 trata dos efeitos da opressão racial, a poesia de 1930 dá foco mais especificamente à causa dessa opressão - uma estrutura econômica de exploração" (2007, p. 141) ${ }^{2}$.

Em um período de desesperança generalizado, um reflexo da quebra da bolsa de valores de Nova Iorque em 1929 e da profunda crise econômica gerada, as condições sociais de racismo, desemprego e pobreza geraram no ideário artístico uma literatura de cunho marxista, proletário e de protesto (RULAND; BRADBURY, 1991). Havia uma predominância de associações comunistas no país e o ideário corrente estava associado a uma tentativa de responder aos tempos de crise econômica, ligando-os à influência danosa do capitalismo 
desenfreado. A escrita literária de Langston Hughes nesta época refletia os tempos de discussão crítica quanto ao cenário econômico e social, com a concepção de que o capitalismo não era um sistema que oferecia apoio às famílias afro-americanas (N. WILLIAMS; M. WILLIAMS, 2007, p. 116).

Já o movimento artístico-literário da Harlem Renaissance (1917-1935), do qual Langston Hughes fez parte e é um dos nomes mais proeminentes, floresceu no Harlem e em outras áreas dos Estados Unidos (DANEMAN, 2015), sendo o bairro também centro difusor de toda a produção artística da comunidade afro-americana do período para outras áreas como a França e o Caribe. O trabalho de Hughes, por exemplo, chegou ao acesso dos escritores francófonos que tratavam da diáspora africana como Léopold Sédar Senghor, Paulette Nardal e Etienne Léro (TIDWELL; RAGAR, 2007, p. 7). Na época de seu surgimento, era conhecido como New Negro Movement (Novo Movimento Negro, em tradução literal) ou Negro Renaissance (Renascença Negra, em tradução literal), mas, como a palavra "negro" caiu em desuso, o termo Harlem Renaissance ganhou força. O movimento possuía a premissa de expressar a representação, identidade e a contribuição do afro-americano através de sua produção artística e cultural, além de oferecer uma nova visão sobre a sua cultura, indo além dos estereótipos raciais até então vigentes na cultura geral. O objetivo era produzir obras artísticas e estudos de afro-americanos, inserindo-os na cultura geral, até então dominada por artistas, literatos e pensadores brancos.

Também nesta época novas técnicas e convenções artísticas ligadas ao modernismo foram criadas. Havia postulados que incentivavam a produção de uma arte espontânea, técnica e estilisticamente inovadora. Os escritores possuíam um espaço privilegiado como aqueles que observavam a sociedade na qual estavam inseridos e, portanto, era seu papel fornecer um entendimento diferente acerca dela (GOVAN, 2007, p. 150). E o que Langston Hughes fez em sua obra foi exatamente fornecer esta visão distinta e crítica da sociedade em sua literatura. Seus contos apresentam o choque, a violência e o preconceito contra os afro-americanos, ao mesmo tempo em que satirizam a exaltação modernista da época, caracterizada pelo postulado "Make it New" de Ezra Pound. O autor utiliza técnicas inovadoras em seu texto literário, mas mostrando pela temática que não há nada de novo naquela sociedade e sim uma continuidade do preconceito racial e da exploração econômica. Os contos também apresentam uma outra representação da linguagem e da maneira de narrar como, por exemplo, os fluxos de consciência e a marcação da oralidade. Logo, o autor emprega técnicas modernistas na forma e no conteúdo de seu texto. 
O conto traduzido, One Christmas Eve, trata de questões contextuais dos Estados Unidos da década de 1930 relativas ao racismo e ao capitalismo como um sistema que promovia desigualdades. A segregação racial retratada e o uso de expressões da linguagem falada indicam que o conto se passa no sul do país durante a véspera de Natal. A época de Natal é representada por uma imagem de consumismo e de aquisição de bens materiais que, por sua vez, estão longe do acesso das personagens afro-americanas. Os dois personagens principais, Arcie e o filho, Joe, passam pelo centro da cidade, mas não podem comprar uma árvore de Natal ou entrar nos cinemas, pois, devido à segregação, alguns cinemas permitiam apenas a entrada de pessoas brancas. Arcie precisa procurar por lojas que vendem artigos mais baratos para comprar seus itens de Natal porque recebe um salário muito baixo como empregada doméstica, que precisa reservar para necessidades básicas como aluguel, comida e roupas.

É possível perceber a discussão que o autor faz acerca da injustiça que o sistema capitalista impõe aos afro-americanos da classe trabalhadora aliada à injustiça racial que a segregação cria. Um contexto de segregação racial, social e econômica é expresso de modo enfático na narrativa, pois enquanto a patroa pode comprar presentes para os filhos, Arcie precisa buscar lojas que vendam produtos a preços baixos para poder comprar um presente para o seu filho. Esta dinâmica que o capitalismo impõe é uma discussão que, no texto de Hughes, está aliada tanto a questões raciais quanto a questões econômicas no sentido de que há um poder de compra despreocupado e liberdade de circulação por parte dos personagens brancos e restrições econômicas e sociais por parte dos personagens negros. Segundo Robert Young (2007), na verdade, não mais se descreve a opressão racial apenas, mas também se apresenta uma explicação sobre a mesma e sua inserção em um contexto socioeconômico maior e, com isto, formam-se bases para um projeto radical que inclui as relações de classe social.

Tais aspectos, tanto contextuais quanto artísticos, ajudam a esclarecer um pouco as nossas bases para uma possível leitura e tradução do texto de Hughes. Isto não significa dizer que esta seria uma única leitura possível ou uma na qual predomine um teor sociológico. Entende-se este trabalho como uma tentativa de compreensão e análise que se insere dentro de um contexto racial e social, refletido nas estratégias narrativas, levando em consideração que havia um discurso corrente de grupos marginalizados que se alçava com o objetivo de assumir uma posição de destaque e propor discussões nos sistemas literário, político e social americanos. 


\section{Traduzindo One Christmas Eve}

Nesta segunda seção, discutimos questões relacionadas ao modo como a oralidade e a variação linguística figuram neste conto e quais interpretações e estratégias de tradução foram privilegiadas. No conto encontram-se duas instâncias literárias que se manifestam distintamente em relação à língua. De acordo com a terminologia proposta por Alexandra de Assis Rosa (2015), há a instância do narrador, que se utiliza, na maioria das vezes, de um discurso que não caracteriza ("non-characterizing discourse"), voltado à norma padrão da língua e há também a instância dos personagens, que se utiliza de um discurso que os caracteriza ("characterizing discourse") e traz maiores possibilidades de apresentar a oralidade (ROSA, 2015, p. 212). Oralidade, neste contexto, relaciona-se ao conceito também exposto por Rosa: seria uma recriação da linguagem falada no texto literário e não uma reprodução integral da fala no texto escrito. O emprego da oralidade enfatizaria o uso linguístico de um personagem ou grupo através da reprodução mimética de elementos de fala que seria caracterizadores da dicção (ROSA, 2015, p. 209). Ao dar a uma personagem um determinado modo de fala que lhe é característico e, ao mesmo tempo, socialmente estigmatizado, marca-se a falta de prestígio que uma variedade ou uso linguístico possui em um grupo social.

Nossa tradução procura acompanhar os discursos do narrador e das personagens, nos quais estão presentes, respectivamente, a norma padrão, socialmente aceita (um discurso que não caracteriza), e as marcas de oralidade relacionadas à linguagem falada (um discurso que caracteriza). É importante observar que tais marcas de oralidade, que indicam o uso não-padrão e que representam uma variedade linguística, o African American Vernacular English (AAVE), ocorrem tanto na voz dos personagens quanto na voz do narrador quando este se vale do fluxo de consciência. O narrador parece dominar o discurso, porém ele também apresenta traços da linguagem falada. Algumas decisões tradutórias relacionadas a este aspecto foram tomadas: quando este narrador assume um discurso voltado à norma, optamos na tradução pelo uso de formas sintéticas e o uso do "havia" ao invés de "tinha" em algumas locuções verbais.

Outro exemplo seria o uso de formas associadas à norma padrão como o pretérito maisque-perfeito como equivalente do Past Perfect, como em "Ele nunca tivera uma e é bom ter essas coisas quando se é criança" (grifo nosso) ao invés de "Ele nunca teve/tinha tido". Ou ainda: "Ficara com as costas doídas" ao invés de "tinha ficado". Por outro lado, nas falas e no fluxo de consciência das personagens utilizamos a forma "pra" e "tá" ao invés de "para" e "está" como indicativo da linguagem oral na tradução. 
Porém, é possível perceber no texto-fonte a utilização de formas contratas da língua inglesa, por exemplo: "it is" para "it's" e "would not" para "wouldn't", seja no discurso do narrador, seja nos diálogos dos personagens. A utilização de tais formas traz um tom mais informal ao texto, considerando-se o fato de que na língua-fonte (língua inglesa), a utilização de formas contratas está relacionada a um registro menos monitorado. Portanto, tentamos empregar na tradução estruturas que estivessem relacionadas a um registro menos monitorado no português; uma delas seria a dupla negativa, conforme o Quadro 1.

Quadro 1 - Fluxo de consciência

What made white folks so darned inconsiderate? Why didn't they come on home here to supper? They knew she wanted to get off before all the stores closed. She wouldn't have time to buy Joe nothin' if they didn't hurry (HUGHES, 1934, s.p.).

Por que os brancos não tinham consideração nenhuma? Por que não vinham jantar? Sabiam que ela queria sair antes de as lojas todas fecharem. $\underline{\text { Não }}$ daria tempo de comprar nada pra Joe se eles não se apressassem.

$\mathrm{Na}$ questão da representação da variação linguística, esta se apresenta no emprego do African American Vernacular English (AAVE). A definição de AAVE utilizada neste trabalho se refere à variedade do inglês americano falado por afro-americanos nos Estados Unidos. Esta variedade surge no processo colonial, em que africanos escravizados foram trazidos do oeste da África para o sul dos Estados Unidos e, com o passar do tempo, estes e/ou seus descendentes migram para o norte, atraídos pela atividade industrial e repelidos de onde estavam pela segregação racial.

Com o processo de aprendizado da língua inglesa pelos africanos escravizados e a transmissão desta a seus descendentes, ela receberia influências das línguas africanas, gerando o AAVE. Esta variedade linguística possui uma gramática e vocabulário próprios, sendo, portanto, uma variedade dentre outras do inglês americano. Ezgeta (2012) faz uma ressalva acerca do uso do AAVE: essa variedade não se estende a toda população afro-americana em todo e qualquer contexto. Os falantes alternam entre ela e o inglês padrão, dependendo da situação comunicativa. No contexto literário do movimento da Harlem Renaissance, o AAVE era utilizado nas obras literárias de alguns autores que desejavam promover uma identificação maior com os leitores afro-americanos (JOHNSTON, s.d.). Essa variedade é utilizada também para dar um senso de identidade, ou seja, o artista expressa e determina a sua existência como indivíduo através de elementos constitutivos de seu grupo.

A opção escolhida para traduzir uma variedade específica de um grupo racial foi o português popular brasileiro. O primeiro motivo para tal escolha seriam traços que ambas as 
variedades compartilham. Segundo Lucchesi (2009; 2012), o português popular brasileiro também se desenvolveu a partir da aquisição defectiva da língua portuguesa pelos indígenas e, principalmente, africanos trazidos ao Brasil para serem escravizados. Ele surge a partir do que Lucchesi define como Transmissão Linguística Irregular (TLI), que seria uma transmissão não formal do português a estes povos escravizados pelo colonizador europeu. Essa variedade surge do contato entre línguas, ou seja, quando ocorre a utilização por parte destes povos de mecanismos das gramáticas de suas próprias línguas para tornar possível a aquisição da nova língua (o português). É possível notar que ambas as variedades, da língua-fonte e da línguaalvo, guardam semelhanças socio-históricas. Além das características relacionadas às origens de ambas as variedades, os juízos de valor como "incorreção" e "desvio" atribuídos a elas são similares. Marcos Bagno atesta que

o estigma e o prestígio atribuídos às formas linguísticas [...] não têm a ver com as características propriamente linguísticas do fenômeno, mas sim com avaliações sociais lançadas sobre os falantes, isto é, sobre os seres humanos que empregam essa ou aquela forma linguística (2007, p. 76, grifo do autor).

Em relação ao AAVE, esta variedade é considerada um desvio da norma da língua inglesa dos Estados Unidos (Standard American English), segundo análises do sociolinguísta norte-americano William Labov (1972). O teórico mostra que estudos anteriores ao que realizou atestavam que a utilização desta variedade implicaria em uma organização e expressão do pensamento e da linguagem que eram ilógicas, querendo dizer que os falantes de AAVE não faziam uma organização cognitiva e linguística que obedecesse às regras que o inglês das classes médias, como a síntese, o uso de estruturas gramaticais completas na estrutura SVO (sujeito-verbo-objeto), entre outras. Em seu trabalho, Labov contesta tais pontos e, a partir de vários exemplos de testes realizados, atesta que o AAVE é uma variedade com organização linguística interna própria e que expressa significados de maneira efetiva, ao contrário do que se postulava anteriormente.

Já no Brasil, o português popular é uma variedade também estigmatizada e isto está relacionado à divisão de classes na sociedade. Segundo Bagno (2007), o uso da norma culta ou de uma variedade estigmatizada sinaliza o grupo social ao qual um determinado indivíduo pertence e determina como será avaliado socialmente. De acordo com o linguista, o uso de uma variedade estigmatizada sinalizaria que o falante é proveniente das classes populares, possui baixa escolaridade, o que gera um preconceito, sobretudo linguístico, pois o falante desta variedade receberá uma avaliação negativa sobre si e terá menores condições de se estabelecer 
social e economicamente se não adquirir e utilizar a norma padrão, sinônimo de instrução e prestígio. O ponto em comum com o AAVE é que falar corretamente, em ambas as sociedades, está relacionado a utilizar aquilo que é considerado a norma ou o standard, um modelo de fala associado às elites. Esta é a ideologia que se impõe acerca da língua em uso, logo, qualquer outro modo de falar significa um desvio que, por sua vez, é julgado à base de preconceito linguístico e social, o que gera e perpetua uma hierarquia social.

Para a tradução, um ponto crucial é a seguinte diferença entre os sistemas linguísticos fonte e alvo: ao passo que o AAVE é uma variedade ligada a um grupo racial, podendo-se até mesmo dizer que é uma variedade específica de um grupo de falantes, o português popular brasileiro não possui tal característica sociolinguística. Segundo Lucchesi, Baxter e Ribeiro (2009):

Não se reconhece no Brasil uma fronteira linguística determinada por fatores étnicos, como ocorre, por exemplo, nos EUA, onde o chamado Black English constitui uma variedade específica do inglês empregada pelos afro-americanos. [...] Se o afrodescendente tem curso universitário e é filho de pais também de nível superior, ele certamente será um falante da norma culta brasileira. Entretanto, infelizmente, a maioria dos afrodescendentes ainda se situa na base da pirâmide social, sendo geralmente falantes da norma popular urbana, ou rurbana (LUCCHESI; BAXTER; RIBEIRO, 2009, p. 31-32, grifo dos autores).

O questionamento que surge é: como conciliar estas diferenças no processo de tradução? É possível? Qual seria o ponto de partida? No processo de tradução foi necessário considerar um aspecto apontado por Vanessa Hanes:

[...] apesar de a variante oral ser bem-aceita há décadas na televisão, em expressões culturais orais, e até em algumas expressões menos "prestigiadas" do português escrito (ex: o cordel), sua aceitação em certos setores de nosso polissistema linguístico ainda é restrita (HANES, 2013, p. 182).

Este foi um elemento norteador de nossas escolhas de tradução, pois na escrita ou na reescrita de textos no Brasil percebe-se uma maior tendência do emprego da norma padrão ou de estratégias que evitem uma linguagem muito marcada como sugerido por Paulo Henriques Britto em A tradução literária (2012, p. 67). No entanto, Hanes afirma que tal tendência está sendo revista e que traduções menos subservientes à norma-padrão estão sendo propostas (HANES, 2013, p. 193). Logo, ponderamos sobre até que ponto determinada estratégia de tradução do texto de Hughes seria ou não bem recebida por conta destas questões. 
Estabeleceu-se que o aspecto mais característico do texto-fonte e que deveria ser representado na tradução seria a variedade do AAVE devido à proposta de representação de um grupo através da oralidade, seguindo o modelo de hierarquização de conteúdos proposto por Britto na obra citada anteriormente. Conforme mencionado, a literatura de Hughes representa seu grupo racial e sua comunidade de fala, sendo essa uma das propostas artísticas da Harlem Renaissance.

Além disso, nesta tradução, partiu-se do princípio de que os elementos da linguagem falada, ainda que reconhecidamente recriados no texto literário, focalizam socialmente uma comunidade e exibem traços linguísticos específicos que criam a visão de alteridade de determinado texto ficcional e a afirmação de um grupo linguístico e social no mesmo (BANDIA, 2015; ROSA, 2015).

Um item de estrutura a ser mencionado seria o fato de o AAVE possuir muitas supressões fonológicas. Alguns exemplos ilustrados por Bailey e Thomas (1998, p. 88-92) são: desvozeamento ou eliminação de plosivas sonoras no final de palavras (ex.: cab: cap; hand: han) e eliminação do /r/ pós-vocálico (ex.: store: sto'). Britto aborda em A tradução literária (2012) que a tradução de supressões deste tipo não é bem recebida em um texto-alvo no português brasileiro, e recomenda investir em marcas na sintaxe que representem uma linguagem falada ou em algumas contrações como "pra" (para) e "tá" (está) etc. (BRITTO, 2012, p. 92). Este fator foi considerado na tradução de One Christmas Eve, mas, ao mesmo tempo, pensou-se também em outras estratégias além dessas que gerassem um texto traduzido que explicitasse o AAVE e a linguagem oral sem resultar em um texto no qual tais marcas de oralidade fossem suavizadas ou até mesmo suprimidas. Esta opção leva em conta o fato de que um texto-alvo que apaga ou silencia marcas de oralidade também silencia grupos de fala que são representados no texto por algum motivo, geralmente aliado à afirmação, como o caso do texto de Hughes. Nos Quadros 2 e 3, apresentamos alguns exemplos nos quais as supressões “aceitáveis" foram utilizadas, conforme proposto por Britto (2012, p. 92), além de escolhas que não obedecem à norma padrão como, por exemplo, o uso de "ir na" ao invés de "ir à".

Quadro 2 - Supressões fonológicas e uso morfossintático não-padrão

\begin{tabular}{|l|l|}
$\begin{array}{l}\text { "If I just had my money, I might leave the supper on } \\
\text { the stove for 'em. Ijust got to get to the stores fo' they } \\
\text { close." (HUGHES, 1934, s.p.). }\end{array}$ & $\begin{array}{l}\text { janta no forno pra eles. Só tenho que ir nas lojas antes } \\
\text { que feche tudo. }\end{array}$
\end{tabular}


Quadro 3 - Supressões fonológicas no texto-fonte e alvo

"Why didn't you stand where I left you?" Arcie demanded loudly. "Tired as I am, I got to run all over the streets in the night lookin' for you. I'm a great mind to wear you out." (HUGHES, 1934, s.p.).

- Por que você não ficou onde eu mandei? - Arcie perguntou alto - Cansada do jeito que eu tô, tive que correr por essa rua todinha, de noite, atrás de você. Bem que você merecia uma sova.

Outro ponto a ser mencionado são as falas de Joe, nas quais ocorre a não concordância entre sujeito e verbo; este é conjugado na terceira pessoa quando o sujeito não é de terceira pessoa, um traço do AAVE, como pode ser observado no Quadro 4. Ezgeta (2012) chama esse fenômeno de durative verbal $-s$ e considera esse fato gramatical uma questão de hipercorreção, já que o AAVE não comportaria a concordância verbal que o inglês padrão exige e os falantes de AAVE empregam o -s com outros pronomes pessoais que não os de terceira pessoa para corrigir seu comportamento linguístico e terminam por fazê-lo em demasia. Já outros consideram ser uma questão de ênfase que o falante impõe a seu discurso. Esse aspecto também ocorre na língua portuguesa, porém de maneira diferente. Ao passo que no AAVE é possível a não concordância entre sujeito na primeira pessoa do singular ('I') e verbo (com o -s de terceira 44 pessoa do plural) no Simple Present, o paradigma verbal no presente do indicativo na língua portuguesa determina uma flexão de número e pessoa específica para a primeira pessoa do singular. Por exemplo, não se diz "eu vai" na variedade popular brasileira, mas o restante do paradigma verbal pode se manter com a mesma flexão verbal: você, ele (a), nós, vocês, eles (a) vai. Ou, ainda, há o modelo de três formas verbais: eu vou, tu, você, ele (a), vocês, eles (a) vai e nós vamo, eliminando o -s da forma "nós vamos" (BAGNO, 2007).

Quadro 4 - A não-concordância entre sujeito e verbo

"I hears they got a Santa Claus down town," Joe said, wriggling into his worn little coat. "I wants to see him." (HUGHES, 1934, s.p.).

- Tão falando que tem um Papai Noel lá no centro da cidade - disse Joe, enrolando-se no casaquinho surrado - Quero ir lá ver ele.

Tal construção em AAVE não é possível em português, portanto buscamos outras soluções que compensassem a tradução desta passagem e que respeitassem as marcas de oralidade (como a supressão fonológica no verbo "estão" e uso de pronome sujeito como objeto direto, parte da variedade popular). Buscamos representar uma variedade estigmatizada na tradução do conto, mesmo com o reconhecimento de que diferenças entre língua-fonte e alvo existem, sendo possível a escolha de estruturas distintas para a tradução ou a não-tradução de certos elementos. 
Mais um elemento a ser comentado nesta tradução seria a linguagem que o autor emprega em seu conto nas passagens que mostram o fluxo de consciência de Arcie e Joe. É possível perceber que há predominância de usos do inglês falado e do AAVE e não do uso da norma padrão por parte do narrador. Alguns exemplos de usos da linguagem falada dão ênfase aos pensamentos da personagem Arcie e, por isso, foram marcados em negrito nas passagens a seguir: o uso de formas contratas; de expressões da língua falada como "darned" para “damned"; e do phrasal verb "to get off"'. Já em relação ao AAVE, pode-se perceber seu uso nas construções com dupla negativa, isto é, o verbo na negativa e o pronome indefinido também na negativa como em “wouldn't... nothing”, o que Labov (1972, p. 226-227) atesta como característica do AAVE; e no uso de verbo no aspecto contínuo indicando ação no presente, como em "And her landlady probably wanting to go out and shop", (HUGHES, 1934, s.p., grifo meu). A dupla negativa também é uma ocorrência do português brasileiro, tanto na norma culta quanto na variedade popular, portanto pôde ser mantida na tradução.

Quadro 5 - Fluxo de consciência de Arcie e traços da linguagem falada

\begin{tabular}{|l|l|}
\hline She looked at the clock on the kitchen table. After & Ela olhou para o relógio em cima da mesa da \\
seven. What made white folks so darned & cozinha. Já passava das sete. Por que os brancos não \\
inconsiderate? Why didn't they come on home here & tinham consideração nenhuma? Por que não vinham \\
to supper? They knew she wanted to get off before & jantar? Sabiam que ela queria sair antes de as lojas \\
all the stores closed. She wouldn't have time to buy & todas fecharem. Não daria tempo de comprar nada \\
Joe nothin' if they didn't hurry. And her landlady & pra Joe se eles não se apressassem. E a senhoria \\
probably wanting to go out and shop, too, and not & certamente querendo sair e fazer compras também, \\
be bothered with little Joe (HUGHES, 1934, s.p.). & e não se incomodar com o pequeno Joe.
\end{tabular}

$\mathrm{Na}$ fala de Joe é possível perceber marcas da linguagem falada na repetição da conjunção "e", que indica uma sequência de pensamentos do menino. Também é possível perceber o uso de "acoming" (partícula a + verbo de ação), que é parte da linguagem falada, característica dialetal de algumas áreas dos Estados Unidos como o Sul e o centro.

Quadro 6 - Fluxo de consciência de Joe e traços da linguagem falada

\begin{tabular}{l|l|}
$\begin{array}{l}\text { Gee, Christmas was pretty. All tinsel and stars and } \\
\text { cotton. And Santa Claus acoming from somewhere, }\end{array}$ & Puxa, o Natal é bonito. Todos os enfeites e \\
dropping things in stockings. And all the people in the & lugar, deixando coisas nas meias. E as pessoas nas ruas \\
streets were carrying things, and the kids looked & $\begin{array}{l}\text { estavam carregando coisas, e as crianças pareciam } \\
\text { happy (HUGHES, 1934, s.p.). }\end{array}$
\end{tabular}




\section{Considerações finais}

A partir da discussão ora apresentada, específica sobre a tradução de um conto de Langston Hughes, podemos tirar conclusões mais gerais como o fato já bastante sedimentado de que a tradução é um estabelecimento de um texto em outra língua que não encara a língua como um sistema absoluto em si mesmo. O texto traduzido é uma nova escrita, uma ressignificação de língua, sociedade e cultura e estes elementos só se completam na recepção do leitor, em como ele irá compreendê-lo e interpretá-lo. Ao contrário do que se pensa, o processo de tradução interlingual é também o de tradução de cultura, história e ideologia; não é um processo isolado que se atém apenas a uma nova codificação de estruturas linguísticas suficientes em si mesmas, pois a tradução pressupõe a presença do estrangeiro, o Outro, inscrito no texto.

Do ponto de vista das escolhas e estratégias para traduzir ao português brasileiro o conto One Christmas Eve, buscamos utilizar variedades não-padrão da nossa língua para representar o uso de uma variedade linguística estrangeira, o AAVE, hoje plenamente aceita pelos linguistas, mas que ainda carrega certa estigma social. Na tradução, nossa preocupação maior

46 era não tornar exótica a fala das personagens negras a ponto de causar um efeito de condescendência no texto em português que adviria de certo conservadorismo linguístico ainda bastante preponderante em nosso sistema de literatura traduzida.

Outra questão que buscamos privilegiar criando diferentes registros linguísticos ao traduzir foi marcar a mudanças de vozes entre personagens e personagens e narrador, caracterizando a identidade de cada um dos actantes na narrativa. A representação da oralidade no texto é capaz de definir socialmente um indivíduo, algo que também se opõe a visão de língua abstrata e homogênea. A língua não é homogênea pela própria expressão de uma heterogeneidade de realizações em sua materialidade, o que possibilita perceber a pluralidade de grupos sociais e indivíduos. As valorações sociais dadas às línguas/variedades linguísticas servem a esferas de poder e à manutenção de hierarquias econômicas e sociais.

Logo, um ato tradutório que se propõe a marcar a oralidade entende a necessidade de trazer estas discussões para o interior do texto traduzido, comprometido com o objetivo de tornar um grupo de fala visível no texto, se colocando contra um projeto ideológico de apagamento de grupos sociais e contra a estigmatização de variedades linguísticas ou variantes não-padrão adotadas por estes grupos, usos linguísticos e grupos estigmatizados justamente porque compõem a parcela da sociedade que não faz parte das esferas de poder. 
Nesse sentido, os tradutores têm um papel ativo e ativista frente à homogeneização das línguas e ao apagamento de identidades de grupos marginalizados ao decidirem por recriar a pluralidade de vozes textuais. Como tudo em tradução, as soluções para esses dilemas de ordem linguística e cultural não possuem uma resposta única que consagre um único modo de traduzir variedades marginalizadas de uma cultura à outra. Nossa proposta foi ao mesmo tempo descritiva ao apresentar nossas soluções para tais dilemas e reflexiva ao pensar de modo mais geral na tradução de oralidade de uma obra estadunidense para um público brasileiro do século XXI.

\section{REFERÊNCIAS BIBLIOGRÁFICAS}

BAILEY, Guy; THOMAS, Erik. Some Aspects of African-American Vernacular English Phonology. In: MUFWENE, S., RICKFORD, J. R.; BAILEY, G.; BAUGH, J. (org.).

African-American English: structure, history and use. New York: Routledge, 1998.

BAGNO, Marcos. Nada na língua é por acaso: por uma pedagogia da variação linguística. $1^{\mathrm{a}}$ ed. $6^{\mathrm{a}}$ reimpressão. São Paulo: Parábola Editorial, 2007.

BANDIA, Paul. Introduction: Orality and translation. Translation Studies, v. 8, n. 12, p. 125-127, 2015. Disponível em:

https://www.tandfonline.com/doi/full/10.1080/14781700.2015.1023217. Acesso em: dez. 2019

BONNICI, Thomas. Teoria e crítica pós-colonialistas. In: BONNICI, T.; ZOLIN, Lúcia O. Teoria Literária. $3^{\text {a }}$. ed. Maringá: UEM, 2009. p. 257-285.

BRITTO, Paulo Henriques. A Tradução Literária. Rio de Janeiro: Civilização Brasileira, 2012.

EZGETA, Marijaz. Internal Grammatical Conditioning in African-American Vernacular English. Maribor International Review. Maribor: v. 5, n. 1, p. 9-26, 2012. Disponível em: http://events.ff.uni-mb.si/mir/files/2012/EzgetaGrammar.pdf. Acesso em: 04 nov. 2017.

FANON, Frantz. Sobre a cultura nacional. In: Os condenados da terra. Traduzido por: Enilce Albergaria Rocha; Lucy Magalhães. Juiz de Fora: Ed. UFJF, 2005. Tradução de: The Wretched of the Earth.

GOVAN, Sandra Y. The Paradox of Modernism in The Ways of White Folks. In: TIDWELL, Jonh Edgar; RAGAR, Cheryl R. (eds.). Montage of a dream: the art and life of Langston Hughes. Columbia: University of Missouri Press, 2007. p. 147-165.

HANES, Vanessa Lopes Lourenço. A tradução de variantes orais da língua inglesa no português do Brasil: uma aproximação inicial. Scientia Traductionis, n. 13, p. 178-196, 2013. Disponível em: https://periodicos.ufsc.br/index.php/scientia/article/view/27445. Acesso em: dez. 2019. 
LABOV, William. The logic of non-standard English. In: LABOV, William. Language in the inner city: studies in the Black English vernacular. Filadélfia: University of Pennsylvania Press, 1972. p. 201-240. Disponível em: http://danielezrajohnson.com/labov_1972_lnse.pdf. Acesso em: dez. 2019.

LUCCHESI, Dante. A deriva secular na formação do português brasileiro: uma visão crítica. In: LOBO, T.; CARNEIRO, Z.; SOLEDADE, J.; ALMEIDA, A.; RIBEIRO, S. (org.). Rosae: linguística histórica, história das línguas e outras histórias. Salvador: EDUFBA, 2012. p. 249274.

LUCCHESI, Dante; BAXTER, Alan; RIBEIRO, Ilza (org.). O Português afrobrasileiro. Salvador: EDFUBA, 2009. p. 31-32.

ROSA, Alexandra Assis. Translating orality, recreating otherness. Translation Studies, n. 8, p. 209-225, 2015. Disponível em:

https://www.tandfonline.com/doi/full/10.1080/14781700.2015.1017833. Acesso em: dez. 2019.

RULAND, Richard; BRADBURY, Malcolm. From Puritanism to Postmodernism: a history of American literature. Nova Iorque: Penguin Books USA Inc, 1991. p. 319-336.

TIDWELL, Jonh Edgar; RAGAR, Cheryl R. Langston Hughes revisited and revised. In:

48 TIDWELL, Jonh Edgar; RAGAR, Cheryl R. (eds.). Montage of a dream: the art and life of Langston Hughes. Columbia: University of Missouri Press, 2007, p. 1-15.

WILLIAMS, Regenia N.; WILLIAMS, Carmaletta M. Mother to Son: The Letter from Carrie Hughes Clark to Langston Hughes, 1928-1938. In: TIDWELL, Jonh Edgar; RAGAR, Cheryl R. (org). Montage of a dream: the art and life of Langston Hughes. Columbia: University of Missouri Press, 2007. p. 106-124.

YOUNG, Robert. Langston Hughes's red poetics and the practice of "Disalienation". In: TIDWELL, Jonh Edgar; RAGAR, Cheryl R. (eds.). Montage of a dream: the art and life of Langston Hughes. Columbia: University of Missouri Press, 2007. p. 135-146.

\section{SITES CONSULTADOS}

AFRICAN AMERICAN ENGLISH. [s.l., s.n., s.d]. Disponível em: https://www.unidue.de/SVE/VARS_AfricanAmericanEnglish.htm Acesso em: dez. 2019.

BLACK ENGLISH. Handout for Psy 598-02. 2001. [s.1., s.n., s.d]. Disponível em: http://www.mathcs.duq.edu/ packer/Courses/Psy598/Black\%20English.pdf Acesso em: dez. 2019.

DANEMAN, Matthew. Harlem Renaissance ushered in new era of black pride. USA Today. 3 fev. 2015. Disponível em: http://www.usatoday.com/story/news/2015/02/03/black-historyharlem-renaissance/22825245/ Acesso em: dez. 2019. 
JOHNSTON, Jessica. An archive for virtual harlem. [S.1., s.n., s.d.] c2015. Disponível em: http://scalar.usc.edu/works/harlem-renaissance/writers Acesso em: dez. 2019.

LIMA, Denilso. Gramática: contracted forms em inglês. c2007. Disponível em: https://www.inglesnapontadalingua.com.br/2010/07/gramatica-as-contracoes-da-lingua.html Acesso em: dez. 2019.

SIDNELL, Jack. Language Varieties: African American Vernacular English (Ebonics). Disponível em: https://www.hawaii.edu/satocenter/langnet/definitions/aave.html Acesso em: dez. 2019.

THE BIOGRAPHY.COM WEBSITE. Langston Hughes Biography. s.d. Disponível em: http://www.biography.com/people/langston-hughes-9346313\#related-video-gallery Acesso em: dez. 2019.

WORD REFERENCE.COM. Acoming, achanging. 20 ago. 2017. Disponível em: https://forum.wordreference.com/threads/acoming-achanging.616625/ Acesso em: dez. 2019.

\footnotetext{
* Carolina Geaquinto PAGANINE - Doutora em Estudos da Tradução (2011) pela Universidade Federal de Santa Catarina. Bacharel em Letras/ Tradução - Inglês (2004) pela Universidade de Brasília. Realizou pesquisa de pósdoutorado (2012-2013) na Universidade Federal de Santa Catarina. Professora adjunto IV na Universidade Federal Fluminense. Niterói, Rio de Janeiro, Brasil.

Currículo acadêmico: http://lattes.cnpq.br/3822561762494940

ORCID: https://orcid.org/0000-0002-8958-1483

E-mail: carolinagp@id.uff.br

** Isadora Moreira FORTUNATO - Mestranda em Estudos de Linguagem na Universidade Federal Fluminense. Graduada em Letras - Inglês (2017) pela mesma instituição. Niterói, Rio de Janeiro, Brasil.

Currículo acadêmico: http://lattes.cnpq.br/0438234176832946

ORCID: https://orcid.org/0000-0001-8634-0548

E-mail: isadora.mfortunato@gmail.com

${ }^{1}$ Políticas legislativas que vigoravam no sul dos Estados Unidos e que eram base para a segregação racial na região. A era de Jim Crow teve fim em 1964, com o Ato dos Direitos Civis.

2"while Hughes's 1920s poetry deals with the effects of racial oppression, the 1930s poetry focus more specifically on the cause of that oppression - an exploitative economic structure" (YOUNG, 2007, p.141; tradução nossa).
} 